\title{
Perception of Musical Similarity Among Contemporary Thematic Materials in Two Instrumentations
}

\author{
S T E P H E N M C A D A M S \\ Institut de Recherche et Coordination Acoustique/Musique \\ (STMS-IRCAM-CNRS) and Ecole Normale Supérieure
}

\author{
S A N D R I N E V I E I L L A R D, O L I V I E R H O U I X \\ STMS-IRCAM-CNRS
}

R O G E R R E Y N O L D S

University of California at San Diego

\begin{abstract}
Free classification was used to explore similarity relations in contemporary musical materials. Thirty-four subsections from the five themes of The Angel of Death by Roger Reynolds were composed identically for piano (Expt. 1) and chamber orchestra (Expt. 2) in terms of pitch, rhythm, and dynamics. Listeners were asked to group together those judged to be musically similar and to describe the similarities between the subsections in each group. Listeners based their classifications on surface similarities related to tempo, rhythmic and melodic texture, pitch register, melodic contour, and articulation. They were to some extent also based on similarity of the mood evoked by the excerpts. This latter factor was more prominent in the verbalizations for the orchestral version. Instrumentation, timbre, and type of timbral change (smooth, disjunctive) also affected classifications in the orchestral version. Perceptual relations among thematic materials within the piece and the interaction of form-bearing dimensions in musical similarity perception are discussed.
\end{abstract}

\section{$\mathrm{T}$ HE perception of similarity between musical materials is a crucial topic in the field of music psychology because it underlies a large part of a}

Address correspondence to Stephen McAdams, CIRMMT, Faculty of Music, McGill University, 555 rue Sherbrooke ouest, Montréal, Québec, Canada H3A 1E3 (e-mail: smc@music.mcgill.ca) or to Sandrine Vieillard, LNMCA, Département de Psychologie, Université de Montréal, C.P. 6128, succ. Centre ville, Montréal, Québec, Canada H3C 3J7 (sandrine.vieillard@umontreal.ca). Authors SM and SV contributed equally to this work.

ISSN: 0730-7829, electronic ISSN: 1533-8312. Please direct all requests for permission to photocopy or reproduce article content to University of California Press's Rights and Permissions website, at www.ucpress.edu/journals/rights.htm. 
listener's musical experience, including the perception of associations between themes or motifs and their variations, the formation of musical categories, and the sense of familiarity. Indeed, the comprehension of musical structure depends on all of these processes. In this article, we examine the kinds of musical similarities that listeners use to group together excerpts of musical materials from a contemporary work in a free classification task. More broadly, this experimental study is a contribution to the question of how similarity relations among new musical materials are apprehended by listeners. The underlying assumption is that listeners use (to-be-discovered) similarity relations among musical materials to organize them into classes, and that their verbalizations concerning what is similar among the excerpts in a given class will reveal something about the similarity cues used. This approach places the work within the framework of similarity and classification of Tversky (1977). Another assumption goes beyond the present study to its implications for the perception, categorization, and recognition of the musical materials within the context of the piece: the classes formed reveal something about the basis upon which musical categories are formed, allowing recognition of materials derived from a given theme as indeed belonging to that theme. This assumption recalls the complex relation between classification, categorization, and recognition studied and developed theoretically by Estes (1994).

McAdams (1989) proposed the concept of form-bearing dimensions to designate the perceptual cues used by listeners to evaluate the similarity between musical materials and derive a coherent perception of the musical structure. Each form-bearing dimension is linked to an elementary auditory attribute like pitch, duration, loudness, spatial position, or any of the attributes associated with timbre (brightness, richness, roughness, attack quality, etc.). Listeners use patterns of variation along these dimensions as perceptual cues. The cues are usually based on a coding of the dimension in terms of discrete categories in most musical structures. Patterns formed from these categories can undergo transformations or variations, many of which still leave the listener with a sense that the transformed material is related to the original. However, the ability to encode relevant musical cues from musical structure is limited by cognitive constraints. For example, a listener's ability to memorize configurations of spatial positions is probably relatively poor compared to the ability to memorize pitch and duration configurations. This means that spatial position would be a less powerful form bearer than are pitch and duration, although the neural and psychological origins of such differences among dimensions are unclear at present, and are even questioned by some composers. Further, in a musical context, memory for similarity cues between two nonadjacent musical patterns can be disrupted by other 
musical elements. Such memory constraints determine a listener's ability to encode and maintain musical similarities, an ability that is required to establish the associative and hierarchical relations that contribute to the mental representation of the structure of the piece.

The notion of similarity is intimately tied to the notion of musical variation: although something has changed, something else remains the same. Musical similarity is at the heart of the use of variations on musical themes, motifs, or materials more generally. The sense of partial sameness allows a link to be established, but also the kind of difference that exists to be appreciated, thus giving rise to a sense of musical development or progression. Relations of similarity among varied materials contribute to classification of the materials. Although there is much debate on the role of similarity in categorization in the cognitive sciences (Medin \& Schaffer, 1978; Nosofsky, 1986, 1992; Rips, 1989; Rosch, 1978; Tversky, 1977), perceptual and structural similarities constrain categorization in a strong way. As Goldstone (1994) points out, it seems likely that low-level (i.e., perceptual) similarities can bootstrap category formation, and the resulting categories can subsequently evolve deeper (i.e., more cognitive) commonalities.

The richness of musical materials allows for the creation of an infinite variety of transformations, most often based on, but certainly not limited to, the manipulation of pitches and durations (McAdams, 1989). Many musical pieces are based on the use of original materials that are later reintroduced in identical or transformed versions. The perception of similarity between these different musical patterns determines the identification of their relations and consequently the comprehension of the musical structure. In sum, listeners recognize the recurrence of musical patterns according to their level of structural and surface resemblance (Matzkin, 2001). The detection of similarity is based on the perception of cues located at the surface as well as at higher hierarchical levels of musical structure. For instance, two musical events can be strictly different at their surface level while being perceived as very similar because of their equivalence at a higher level of structure, such as that represented by time span and prolongational reductions (Bigand, 1990; Serafine, Glassman, \& Overbeek, 1989).

With a few notable exceptions, work on the representation of musical patterns has focused on Western tonal music and much less on nontonal contemporary music. In nontonal musical contexts, a large variety of unfamiliar musical materials are encountered, and the transformations and variations go beyond the usual exploitation of pitch and duration structures based on conventionally defined categories and hierarchical relations among categories. It follows that pattern processing cannot be entirely based on previous conventional schematic knowledge in such cases. 
Lerdahl (1989) has suggested that there is no a priori reason to think that tonal and atonal music are processed by different cognitive mechanisms. Their differences in processing would primarily be due to differences in the hierarchical structure present in the music itself. His model of the perception of atonal music attempts to account for the way listeners integrate atonal hierarchical structure. According to this model, the perception of prolongational structure (adapted from Lerdahl \& Jackendoff, 1983 ) could be based on an atonal pitch space, and contextual reinforcement provides the possibility to elaborate a structured representation of relations among events. Furthermore, the model postulates that the structural hierarchy of atonal music can be inferred through the relative salience of events determined by attack quality, metric position, loudness, timbral prominence, event intensity and duration, and motivic development. Indeed, he concluded, the stability conditions found in tonal music reduce to salience conditions in atonal music.

In testing these claims, Dibben (1994) confirmed the existence of an internal representation of hierarchical structure in tonal music, but was unable to demonstrate its existence in atonal pieces by Schoenberg. She concluded that the less hierarchically organized pitch relations of the atonal style did not allow listeners to use such pitch relations to apprehend the piece. This led her to suppose that the perception of relations among musical features in atonal music would be more associative than hierarchical. Nevertheless, in a subsequent study using Schoenberg piano pieces, results showed that the relative structural importance of events in atonal music could be derived from acoustic salience, voice leading, dissonance, and metric structure (Dibben, 1999). So hierarchical structure would appear to be encodable by listeners in nontonal music after all, confirming the beliefs of many composers and theorists.

Because the organization (hierarchical or not) of nontonal relations does not completely match with conventional musical schemata, presumably acquired implicitly by Western listeners, new cognitive constraints probably appear in the processing of contemporary musical patterns. Thus, the critical issue is the way the cognitive system adapts to new uses of musical materials in order to perceive the relations among them. More specifically, this raises the question of similarity perception without previous schematic knowledge allowing for the integration of nontonal materials into a musical structure.

\section{Thematic Materials from The Angel of Death}

Our study aims to explore how listeners perceive similarity relations among the materials from the contemporary piece The Angel of Death by 
Roger Reynolds (2001). This piece was composed for piano solo, a chamber orchestra of 16 musicians, and computer-processed sound. Our goal was to describe the criteria underlying listeners' perceptions of similarity among subsections of the thematic materials.

The composer created the five themes to perform specific musical functions within the formal structure of the piece (see Reynolds, 2004). Each theme possesses a strong identity that was conceived by the composer to play an important role in the musical form. Reynolds proposed evocative titles for the themes: Equilibrium in Extremis, Contradictory Assertion, Tremulous Uncertainty, Jagged Rips, and Interior Line in order. Further, each theme was conceived as a series of concatenated subsections, one of which was the central identity, or "core element" in the composer's terms, of the theme. Lalitte et al. (2004) have proposed a detailed analysis of the musical functions filled by each subsection within the theme as a whole. Given that these functions would emerge within the context of the whole theme, we did not expect them to play a role in the current experiment. The following descriptions of the thematic materials have thus been oriented toward the surface characteristics that we thought were likely to be salient in the free classification task.

The entire themes occur during one half of the piece conceived as having a clear sectional structure: Themes 1 and 3 occur in the piano and Themes 2, 4, and 5 in the orchestra. But the thematic materials also occur in derived form in the other part of the piece, which has a more diffuse, organic nature. The composer labeled the two parts $\mathrm{S}$ (sectional) and $\mathrm{D}$ (domain), respectively. The core element subsection of each theme occurs in nearly identical form at exactly the same point in time in each part. Derived materials surrounding the core elements are drawn from the same theme in the D part. One of the main structural features of the piece resides in the principle of instrumental reversal of thematic materials across these two parts. For instance, the solo piano plays in one part what the chamber orchestra plays in the other part, and vice versa (see Reynolds, 2004, for a more detailed presentation). This feature, and the fact that the thematic materials would be used as source materials in the computer layer, required that they be composed in nearly identical piano and orchestral versions. This allowed us to perform separate experiments on both instrumentations of the themes and to explore the additional effects of instrumentation on musical similarity.

In his notebooks, the composer summarized the nature of Equilibrium in Extremis, the first theme of the piece, as: "Two lines, often complementary; extreme behavior by one elicits another extremity [an adaptive world]." This theme has the overall form of an "X" with extreme registers at the beginning and end, and convergence toward the middle register in the middle of the theme followed by a divergence. It starts in 
Subsection 1 with long-duration pedal notes in the bass and irregularly repeating notes with grace-note figuration in the extreme high register. The repeating notes are progressively embellished in Subsections 2 and 3 and become legato running passages that are fairly regular in Subsection 4. The apparent speed is more fluctuating in the core element (Subsection 5 ) with a fermata at about two thirds of the way through it. Beyond this point, two lines emerge in counterpoint that are rhythmically independent at first in Subsections 6 and 7 and then become synchronized in the Subsections 8 and 9. In the orchestral version, the initial pedal tones are in the brass and low strings and the high register is taken by piccolo and flute, highlighted by high metal percussion and string harmonics. As the main melodic line descends, it passes from flute to clarinet and then to trumpet in the core subsection, with subsequent relaying between these three instruments. In Subsection six, the violins take the two contrapuntal lines, followed by a hocketing between mallet percussion and the clarinets. As the rhythmically synchronous last section arrives, the full orchestra is involved in the hocketing.

The second theme, Contradictory Assertion, is characterized by rapid and irregular changes of chords with wide contrasts of dynamic level. Reynolds posited this theme as a matrix of dominating chords with softer interstitial runs in parallel motion. He specified that "some [chords] are unique to an individual subsection of the theme, others encompass the first three or last three subsections, some occur over a larger span, bracketing the core element." The chords alternate dynamic level in the first subsection. The soft chords are at times replaced by rapid melodic figuration in Subsection 2, and then the alternating-level chords return in Subsection 3. The core element (Subsection 4) has two ff lines of synchronized 16 th notes, the rhythmic regularity of which begins to warp near the end and then resynchronizes to arrive in Subsection 5 with alternating chords again. Subsection 6 returns to rapid two-line rhythmic synchrony and then leads to the last subsection, which again has alternating $s f f z$ and soft chords. In the orchestral version, the chords are variously voiced across the different instrument families, the sffz chords being notably punctuated by the brass. The instrumentation is consistent for each chordal family. Mallet percussion plays the rapid passage in Subsection 4, whereas Subsection 6 starts in the clarinets and moves to the strings and then to mallet percussion.

Theme 3, called Tremulous Uncertainty, has a simpler sectional structure and was characterized by Reynolds as: "alternating, out of phase, dyadic tremolos, irregularly changing, occasional arpeggiation [an unstable world]." The alternation occurs in each of two lines, which move in and out of synchrony with one another. Both lines are in the middle register in Subsection 1, start slightly more separated and then converge in 
Subsection 2 (the core element), diverge in Subsection 3, and then both move slightly downward in Subsection 4. All of the subsections are played legato except the third, which is staccato. In the orchestral version, the alternating lines are generally played by instruments of the same family at any given moment, but are passed between families. Sustained $p p$ notes in the woodwinds and glissandi in the strings highlight the converging motion of mallet percussion in Subsection 2, simulating the effect of the piano sustain pedal. The globally descending figure in Subsection 4 is underlined by a timbral descent from flutes to clarinets in the woodwinds and from viola to cello to contrabass in the strings.

The fourth theme, entitled Jagged Rips, is defined by its strong and characteristic directional gestures. Subsection 1 starts very high and descends to a very low register in cascades (rips) with sudden reversals in direction (jags). Subsection 2 rises and falls and Subsection 3 rises to the top and stops on a silent fermata. Subsection 4 presents a very brief idiosyncratic soft descending passage with a repeating note in the upper register that overlaps temporally with the last half of the descending line. According to Reynolds, the core element that corresponds to the fifth subsection has the greatest variety of slopes, ranges, and forms of disruption. Subsection 6 rises again and then there is an abrupt break at the beginning of Subsection 7, which starts slowly in the lowest register, rises and crescendos to a couple of very high grace-note figures, and then ends on a complex pattern that diverges into two lines. In the orchestral version, the cascading lines are passed from instrument to instrument in overlapping runs, using the jags to achieve a seamless timbral transition. The timbral motion serves to augment the dramatic form of the cascading rips. A timbral crescendo involving the brass in Subsection 7 is particularly powerful in its emotional impact.

Finally, the fifth theme, entitled Interior Line, the longest and most extended thematic element, was designed by Reynolds to be "chordal but with a weighted, linear emphasis." It is lyrically melodic, with certain notes held to give the harmonic resonance characteristic of this theme. The apparent speed fluctuates considerably throughout, giving a sense of elasticity. Subsection 1 presents the initial melody line, which is countered in Subsection 2 by a rapid and irregularly repeating $\mathrm{B} b$, ornamented by grace-note flourishes. The two notions of melody and grace note flourish are combined in Subsection 3 where the repeated and slowly changing principal notes are embellished. Subsection 4 is again more linear but with intertwined and rhythmically fluctuating ostinatic tracings in the same register. The core element (Subsection 5) is quite different in being clearly chordal, with a progression that is emblematic in the piece. One note of each chord occurs as an anacrusic grace note leading into the chord, and these grace notes suggest an embedded line in keeping with the character- 
istic texture of the theme. Subsections 6 and 7 return to the more melodic, lyrical nature of the theme. In the orchestral version, the melody is treated in the style of Klangfarbenmelodie with smooth transitions across instruments. The sustaining of resonant tones provides a coherent variation in timbre that preserves and enhances the theme's linearity.

As noted above, the themes were conceived as a concatenation of several subsections, although it should be kept in mind in examining the results of the experiments reported here that each theme is in fact a full musical statement. Several cues such as tempo, the frequency of occurrence of pitches, melodic and rhythmic patterns, and harmonic and metric relations link the subsections together. We would thus hypothesize that listeners should recognize similarity relations among many of the subsections of a theme. However, because the composer also designed each theme to have a certain degree of internal variation to make it interesting as a musical whole, some subsections may be perceived as more similar to those of other themes. So the exploratory question that concerns us within the larger project around The Angel of Death is the following: given that the thematic subsections are used as basic building blocks for the composition of the electroacoustic part, for the combination and transition sections of the piece, and as a basis for the derived Domain part of the piece, what are the relations of similarity among subsections within and across themes? This latter point is important for projecting the study of the materials in isolation into the full musical context. Indeed, in the large transitional sections, materials derived from one theme are prominent at the beginning, and the dominance relation then slowly evolves toward the materials of the other theme. These regions involve transitions between Themes 1 and 3 (TR $1 \rightarrow 3$ ) in the piano layer in $S$ and in the orchestra layer in D, and between Themes 2 and 4 (TR2 $\rightarrow 4$ ) in orchestra in $\mathrm{S}$ and in piano in D. Other regions involve the coexistence of themes in either the piano or orchestra layers. The combination regions include COMB2/4 (combination of Themes 2 and 4 ) in piano in $S$ and in orchestra in $\mathrm{D}$, and COMB3/5 and COMB1/2/3, both in orchestra in $\mathrm{D}$ (see Reynolds, 2004, for more detail concerning these regions). So the potential for interaction and confusion among thematic subsections existed at the outset of the project. It should be noted that the current study was performed, and the results made available to the composer, before the composition of the $S$ and $\mathrm{D}$ parts was begun.

\section{Aims of the Study}

To characterize the perception of similarity between the subsections for a given instrumentation (piano or orchestra), we used a free classification 
task in which subsections from the thematic materials were presented. Listeners were asked to group excerpts together according to their musical similarity, and then to describe verbally how all the excerpts of each class were similar. Therefore, the classification is itself an expression of their similarity judgments from which quantitative measures can be derived in the form of an incidence matrix. (Given our interest in how class relations among thematic subsections would correspond to original theme structure, we felt that free classification was the appropriate method. Multidimensional scaling approaches with dissimilarity ratings in paired comparisons would be impractical because of the number and duration of our excerpts.) We expected that there were a number of properties upon which the classification could potentially be based. These might include surface characteristics such as tempo, event density, harmonic density, register, melodic and rhythmic contour, articulation, and texture, or more structural features such as underlying harmony or hierarchically important pitch distributions, both derived from the hierarchy of pitch materials conceived by the composer (see Reynolds, 2004, for more detail on this point). Given that the pitch palette and harmonic structure would be completely new to the listeners, it seemed probable that surface features would play a stronger role in the classification task.

\section{Experiment 1: Piano Versions}

In the first experiment, listeners characterized their perceptions of similarity among subsections of the thematic materials in the piano versions by way of a free classification and verbal description task.

\section{METHOD}

\section{Participants}

Eighty-nine participants with ages ranging from 20 to 47 years $(M=29, S D=6.7)$ performed the experiment. None reported having hearing problems, and all were paid for their participation. Nine listeners were removed because of data recording problems. Two others who had extreme numbers of classes were also removed: one male musician had only one class, and one female nonmusician had 17 classes, a number of classes that was more than three standard deviations above the mean of the population. Of the remaining 78,39 had no musical experience ( 20 women) and 39 had from five to 25 years instrumental practice ( 21 women). In the latter group, 11 were professional musicians and 28 were actively practicing amateurs.

\section{Stimuli}

Thirty-four musical subsections, as defined by the composer, came from the five themes of the piece. The themes contained nine, seven, four, seven, and seven subsections, respectively. They were performed on a Steinway grand piano by Jean-Marie Cottet in the Espace 
de Projection concert hall at IRCAM and were digitally recorded in 24-bit stereo format at a sampling rate of $48 \mathrm{kHz}$. The recordings were converted to 16-bit stereo files with a sampling rate of $44.1 \mathrm{kHz}$ for the experiment. The subsections of the themes were extracted digitally from the sound files with appropriate rise and decay envelopes. The ramp durations were adjusted by ear to avoid clicks and to perturb minimally the temporal envelope of the musical signal. The durations of the subsections varied from 2.6 to $29.2 \mathrm{~s}^{1}{ }^{1}$

\section{Procedure}

Listeners were not informed as to the number of themes or name and number of subsections for each theme. The 34 subsections were symbolized by randomly numbered squares displayed on a computer screen in a random pattern. Listeners clicked on a square with the computer mouse to hear it. They were instructed that they first had to listen to all subsections and then had to group together those that had a musical "family resemblance." This task was a free classification paradigm in which the participants chose their own similarity criteria to create different classes. The squares could be displaced on the screen with the mouse and the corresponding sounds listened to as often as needed to compare among excerpts. The listeners could put any number of subsections into a class and make as many classes as desired. There was no time limit. Once listeners were satisfied with their classification, they were asked to listen again one last time to verify and then to describe verbally the similarities between the subsections within each class. The experimenter noted the subsections in each class, and the listeners wrote down the verbal descriptions. The musical stimuli were presented at a comfortable listening level that allowed the full dynamic range of the excerpts to be heard. The level was determined at the outset by the authors. The experiment lasted about an hour.

\section{Equipment}

The classification task was run on a NeXT computer with FTS, Max (Lindemann, Dechelle, Smith, \& Starkier, 1991) and PsiExp (Smith, 1995) software packages. Musical stimuli were amplified with a Yamaha P2075 power amplifier and presented binaurally over a Sennheiser HD 520 II headphone. Listeners were seated in an IAC double-walled sound isolation booth.

\section{RESULTS}

Listeners created from two to 12 classes $(M d n=6$, mode $=5)$. A between-subjects analysis of variance (ANOVA) with factors Gender (2) and Musical Expertise (2) revealed no significant effects (all $F<1$ ). Each listener's classification was converted into an incidence matrix in which each cell indicated whether two subsections were grouped together $(1=$ same class, $0=$ different classes $)$. Incidence matrices were then summed into separate cooccurrence matrices for musicians and nonmusicians, in which the proximity of each pair of subsections corresponded to the number of listeners putting the two subsections in the same group. For each group, this gave a lower triangular matrix without diagonal. The correlation between the matrices was highly significant,

1. The stimuli for both experiments, with a visual depiction of the tree structure, may be found at $\mathrm{ftp}: / / \mathrm{ftp}$.ircam.fr/private/pcm/angel/classification_format.zip, where "format" should be replaced by "aiff" or "wav" as needed. A demonstration version of these experiments will be included in the e-book on the Angel Project (McAdams \& Battier, 2005). 
$r(559)=.82, p<.0001$. Therefore, the data were combined in subsequent analyses. $^{2}$

\section{Cluster Analysis}

Hierarchical clustering analysis was used to discover underlying patterns of similarity in the psychological data (Daws, 1996; Kruskal, 1977). The cooccurrence matrix for all listeners was converted into a dissimilarity matrix in which cells represented the proportion of listeners placing the two stimuli in separate groups. A hierarchical tree structure was computed on the resulting matrix using the complete linkage (farthest neighbor) method (Figure 1). This method uses items that are the farthest from one another to form clusters and creates more contrasted classes that are more compact than does the single linkage method, for example. In this representation, the lower two elements (or groups of elements) are joined in the tree, the higher is their similarity. The labels indicate the theme and subsection (e.g., 1.5 is subsection 5 of Theme 1). The correlation between the dissimilarity matrix and the cophenetic matrix (distances between elements in the tree structure) shows that the tree structure represents $75 \%$ of the variance in the data, $r(559)=.869, p<.0001$.

The differentiation between classes of stimuli was made by setting a threshold dissimilarity value of $.9 .^{3}$ This gave four classes. Figure 1 clearly shows that although the number of classes is close to the number of themes, there is some dispersion of theme subsections. Theme 1 is split between Class 2 (44\% of its subsections) and Class $3(44 \%)$. With the exception of Theme 1, the second largest and most varied theme, the majority of the subsections of the other themes are found in a single class, Class 2 for Theme $2(71 \%)$, Class 3 for Theme $3(75 \%)$, Class 1 for

2. The unexplained variance in the correlation between musicians' and nonmusicians' co-occurrence matrices being $32 \%$, we decided to test whether this variance was systematically related to musical expertise. The participants for each group were split into two groups of 20 and 19 listeners. The co-occurrence matrices for each subgroup were computed and all correlations among groups were performed, and the $95 \%$ confidence intervals on the correlation coefficients were determined. If the unexplained variance was due to a systematic effect of musical training, we would expect the intragroup correlations to be significantly higher than those between groups. The correlation coefficient between the two subgroups of musicians was significantly higher than (i.e., outside the $95 \%$ confidence interval of) all of the other coefficients. However, the coefficient between the two nonmusicians' subgroups were not significantly different from the coefficients between subgroups of musicians and nonmusicians. The degree of difference between groups was thus not significantly different from that between subgroups of the same group. We therefore conclude that the differences are not systematically related to musical expertise.

3. The threshold value for class separation was chosen so that a single value for the tree structures of Experiments 1 (piano) and 2 (orchestra) would give a number of classes as close as possible to the number of themes (5) defined by the composer. The cutoff value of .9 yielded four classes for piano and six for orchestra. Cutting the tree at .8 , for example, yielded eight classes for both piano and orchestra. 


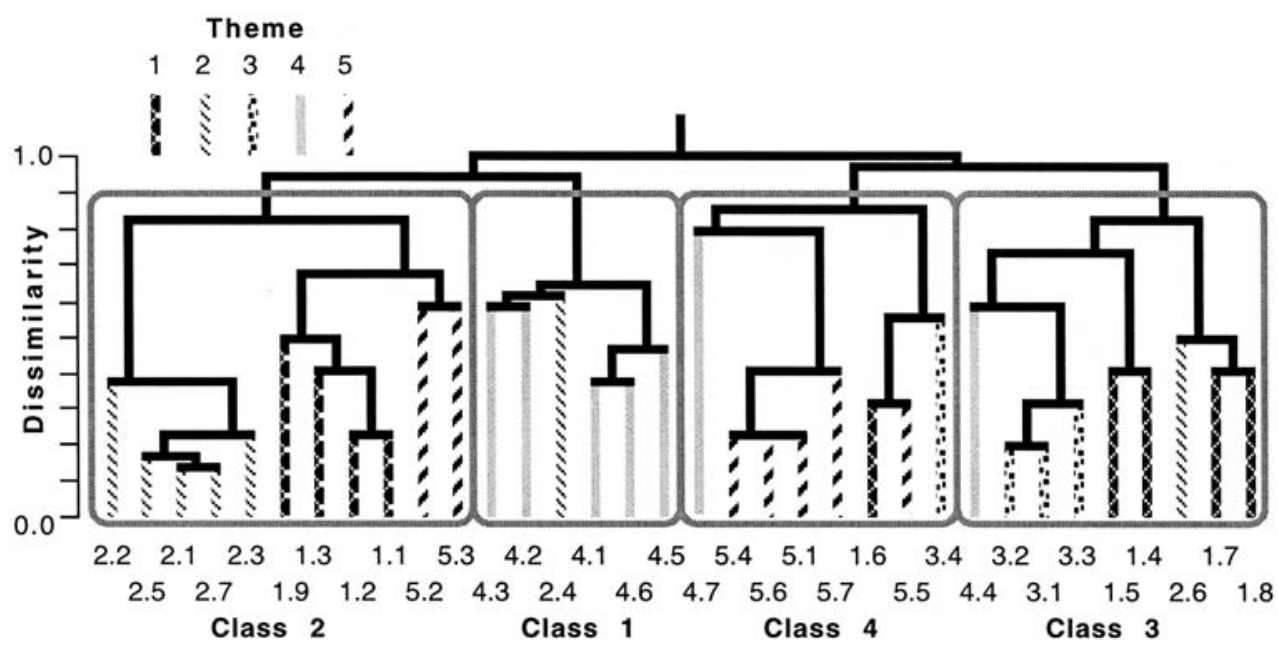

Fig. 1. Hierarchical clustering tree (complete linkage method) for free classification data (Expt. 1) with the piano versions of thematic subsections. The labels of each final branch correspond to $<$ Theme.subsection $>$. The themes are distinguished by line textures.

Theme $4(71 \%)$, and Class 4 for Theme $5(71 \%)$. Themes 2 and 5 have the highest similarity values across subsections within a given class (i.e., the subsections join at the lowest levels of the tree). Note that differences in duration between the subsections explain only $1 \%$ of the variance in the dissimilarities, $r(559)=.11, p<.01$.

\section{Verbalization Analysis}

Listeners described the characteristics that made the subsections part of the same group. For example, listener S5 classed the 34 subsections into the four groups shown by the thick gray ellipses in Figure 2 and produced the following verbal units concerning the similarities among items in each group: Group 1 was labeled "dynamic, rapid repetition of the same notes," Group 2 "timbre, very characteristic tremolo," Group 3 "velvety atmosphere, serial music genre," and Group 4 "virtuoso, chromatic, characteristic." The next stage in the analysis consisted of assigning the verbalizations provided by the listeners to the classes found with the cluster analysis. The verbalization analysis was based on the following principle: the groups of subsections corresponding to a listener's classification were compared with the classes resulting from the cluster analysis. If the subsections of an individual listener's group included more than $50 \%$ of the subsections in a class, the verbalization for that group was assigned to the class. Note that it is possible for a given verbalization to be assigned to more than one class if the listener-defined group includes at least $50 \%$ of 


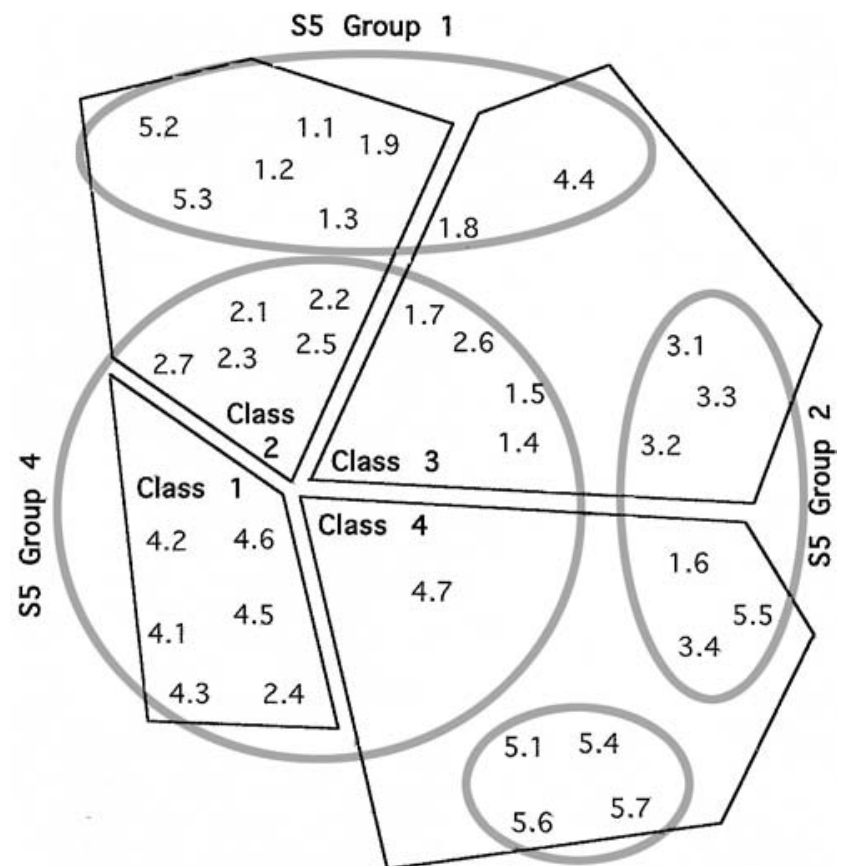

S5 Group 3

Fig. 2. Example of the method of verbalization analysis. The 34 subsections are indicated by $<$ Theme.subsection>. The polygons enclose subsections belonging to one of the four classes derived from the group tree structure in Figure 1. The gray ellipses enclose the subsections placed in four groups by listener S5. Verbalizations produced for a given group are assigned to the class if the group contains more than $50 \%$ of the subsections of that class. This is the case only for Group 1 (assigned to Class 2) and for Group 4 (assigned to Class 1).

the subsections of more than one class derived from the tree structure. Consider again the example of listener S5 in Figure 2. The thin solid polygons represent the four classes derived from the tree structure. Group 1 contains $54 \%$ of the elements of Class 2 and $22 \%$ of the elements of Class 3 . The verbalization for this group was thus assigned to Class 2. Group 2 contains $33 \%$ and $37 \%$ of the elements from Classes 3 and 4, respectively. Group 3 contains $50 \%$ of the elements of Class 4 . The verbalizations for Group 2 and Group 3 were assigned to no class, because none of the percentages of correspondence exceeded $50 \%$. Group 4 contains $100 \%$, $45 \%, 44 \%$, and $12 \%$ of the elements of Classes 1 to 4 , respectively. This verbalization was thus assigned to Class 1 . This technique ensures that verbalization assignment is performed in a rather conservative manner, avoiding spurious distribution.

The 78 participants formed a total of 488 classes, each with a verbal unit with the exception of five that were labeled "unclassifiable." Of 
these units, 156 were assigned to the four classes in the tree structure: $39,38,43$, and 36 to Classes $1-4$, respectively. A summary of the most frequently employed terms assigned to the classes with this method is presented in Table 1. This reduction was achieved in two stages. First, the key terms in each verbal unit were separated. For example, "virtuoso, chromatic, marked" would be considered as three separate terms. In the interest of economy of presentation, the second stage consisted of regrouping the terms according to similar categories (e.g., contour, texture, articulation, mood) as shown in each entry in Table 1, and their counts were pooled. Class 1 is characterized by rapid, chromatic scale passages in upward and downward directions, with abrupt, hammered, accentuated, jerky, and rebounding rhythms. Class 2 is rhythmically syncopated and choppy, with loud, insistent, hammered chords and has an overall character of aggressiveness. Class 3 is rapid and fluid, with connected cascades that are rhythmically regular, light, soft, and melodious with a round sonority. Class 4 is slow and irregular rhythmically, melodically linear, harmonic, and soft and has a sad, nostalgic, calm, and lyrical character.

\section{TABle 1}

\section{Most Frequently Verbalized Groups of Similar Terms Assigned to the} Four Classes of Piano Materials

\begin{tabular}{|c|c|c|c|}
\hline Class 1 & Class 2 & Class 3 & Class 4 \\
\hline $\begin{array}{l}\text { Ascending, descending } \\
(27)\end{array}$ & $\begin{array}{l}\text { Struck, hammered, } \\
\text { insistent, attack, } \\
\text { staccato, cut off, } \\
\text { accentuated, broken, } \\
\text { interrupted (29) }\end{array}$ & $\begin{array}{l}\text { Rapid tempo, speed } \\
\text { (18) }\end{array}$ & $\begin{array}{l}\text { Slow, speed, tempo } \\
\text { (11) }\end{array}$ \\
\hline $\begin{array}{l}\text { Progression, chaining, } \\
\text { series, sequence (13) }\end{array}$ & $\begin{array}{l}\text { Rhythmic, jerky, } \\
\text { repeated, syncopated, } \\
\text { choppy, dynamic, } \\
\text { rebounding }(27)\end{array}$ & $\begin{array}{l}\text { Chaining, cascade, } \\
\text { series, movement, } \\
\text { connected, fluidity } \\
(16)\end{array}$ & $\begin{array}{l}\text { Melodic, motif, line, } \\
\text { linear (10) }\end{array}$ \\
\hline $\begin{array}{l}\text { Rapid tempo, acceler- } \\
\text { ation (12) }\end{array}$ & Loud, strong (14) & $\begin{array}{l}\text { Rhythmic, repetitions, } \\
\text { regular (11) }\end{array}$ & $\begin{array}{l}\text { Sad, supple, nostalgic, } \\
\text { melodious, lyrical, } \\
\text { fluid, calm, appeased } \\
\text { (8) }\end{array}$ \\
\hline Scale $(8)$ & Chord (7) & $\begin{array}{l}\text { Light, soft, tranquil, } \\
\text { melodious, appeased } \\
\text { (10) }\end{array}$ & $\begin{array}{l}\text { Rhythm, rebounding, } \\
\text { irregularity }(5)\end{array}$ \\
\hline $\begin{array}{l}\text { Abrupt, broken, cut } \\
\text { off, percussive, ham- } \\
\text { mered, struck, } \\
\text { accented (8) }\end{array}$ & High (6) & $\begin{array}{l}\text { Timbre, sonority, } \\
\text { roundness, color (6) }\end{array}$ & Soft, intensity (5) \\
\hline Chromatic (6) & Aggressive, violent (5) & $\begin{array}{l}\text { Medium (register), } \\
\text { register (6) }\end{array}$ & Harmonic (4) \\
\hline $\begin{array}{l}\text { Rhythmic, jerky, } \\
\text { rebounding }(5)\end{array}$ & Rapid tempo (3) & $\begin{array}{l}\text { Harmony, tonal }(4) \\
\text { Chromatic }(4)\end{array}$ & \\
\hline
\end{tabular}

NotE-The total number of verbalizations represented by each set of terms is indicated in parentheses. The verbalizations were originally produced in French and are presented here in approximate translation. 
The musical features revealed both by the cluster and verbalization analyses are clearly primarily related to the surface features of the musical materials, for example, contour, tempo, rhythmic and melodic characteristics, register, and loudness. At times, however, some listeners evoked the atmosphere created, for example, aggressive, nostalgic, and tranquil. Given that the aim of the project as a whole was an interaction between the artistic and scientific aims, the composer was asked to interpret in his own words the tree diagrams by describing the characteristics that seemed to him to be common to the excerpts in each of the four classes of the tree structure (without having been exposed to the verbalization results of the experiment). He did this by listening to the excerpts as the participants had but with reference to the diagram in Figure 1 . Note that he actually interpreted two hierarchical levels in Classes 2-4.

- Class 1: Rapidity and evenness of motion. Conjunctness and consistency of interval size. Directionality (either upwards or downwards). Energetic, assertive mood. Wide range is a frequent feature. Unusual features: 4.3 and 2.4 have two lines simultaneously and there is a break in evenness of motion in 2.4.

- Class 2: Gestural quirkiness (uneven and unpredictable events). Disjunct character. Tendency to reiterate individual (not groups of) elements. Characteristics of the two subclasses:

a. $(2.1,2.2,2.3,2.5,2.7)$ Staccato chords. Irregular and widely varying dynamic level. Irregular spacing over time.

b. $(1.1,1.2,1.3,1.9,5.2,5.3)$ Interspersed with irregular groups of repeated, individual pitches (high and mid range). Locally assertive and directional gestures (goal seeking). Harmonically heterogeneous.

- Class 3: Rapidity and fluidity of motion. Registral consistency (lack of directionality). Characteristics of the two subclasses:

a. $(1.4,1.5,3.1,3.2,3.3,4.4)$ Harmonic blur. Tendency toward a fluttering alternation of pitches. Smooth, featureless.

b. $(2.6,1.7,1.8)$ More articulate quality. Presence of specific articulating features (except for 1.7). More assertive or urgent mood.

- Class 4: Gentle mood. Elastic fluctuation of speed. Characteristics of the three subclasses:

a. $(1.6,3.4,5.5)$ Cadential trailing off of each segment. Tenderness of mood. Harmonic movement is significant.

b. (4.7) Single lines. Wide pitch and dynamic range. Strong, cumulative, upward directionality.

c. $(5.1,5.4,5.6,5.7)$ Single lines. Harmonic consistency. Some ostinatic recursiveness. Lyrical mood.

The composer emphasized in performing this descriptive interpretation that there was a strong sense of how the consistency of the instrumental 
medium (piano) allowed clarity of access to the musical design of the materials, an aspect that is quite different for the orchestral materials to be examined in Experiment 2. A comparison of the composer's and the collective listeners' descriptions shows qualitative agreement on many characteristics, but differences in expression on others, for example, "gestural quirkiness (uneven and unpredictable events)" in Class 2 appears as "rhythmic, jerky, syncopated, choppy, dynamic, rapid tempo, broken, rebounding" in the collected verbalizations of the participants.

\section{DISCUSSION}

The similarity structure of the piano versions of thematic materials from The Angel of Death as revealed by the classification task shows that many of the subsections from a given theme were grouped in the same classes or subclasses. Even though they do not always match with the original structure of the thematic materials, some of the exceptions to thematic groupings are instructive concerning the perceptual cues upon which listeners seem to have based their classifications. Subsections 1.6 and 3.4 were often classed with 5.5 and not with their respective thematic subsections because they are all characterized by a soft, slow harmonic movement with a tender, contemplative mood. With the exception of 1.6, Theme 1 subsections were split into two groups that are distinguished by the presence of repeated, accented notes in Class 2 and chromatic runs in Class 3. Subsections 2.4 and 2.6 are different from the rest of Theme 2 in being chromatically melodic rather than having hammered chords alternating with softer chords or melodic figurations: Subsection 2.4 was grouped with Theme 4 materials due to its rapid motion and clear directionality, while 2.6 was joined with subsections of Theme 1 because of the chromatic staccato texture. Subsections 4.4 and 4.7 depart from the Jagged Rips nature of the other subsections of Theme 4: Subsection 4.4 is grouped with three subsections from Theme 3 that share a fluttering alternation of pitches, whereas Subsection 4.7, a singleton that has only a distant grouping with other subsections, has a unique wide-ranging arpeggio with a high-pitched flourish. Subsections 5.2 and 5.3 distinguish themselves from the rest of Theme 5 in being less lyrical and linearly melodic, due to the inclusion of fast, repeated notes that make them more similar to some of the Theme 1 materials.

The verbalization analysis suggests that listeners focused primarily on surface features related to melody, rhythm, articulation, and gesture, and to a much lesser extent on harmony, dynamics, and timbre. Terms related to pitch and melody include notions of register, conjunctness/disjunctness of intervals, pitch range, contour features (alternation, smoothness or choppiness of trajectory), directionality, element repetition, and singleness or multiplicity of line. Duration- and rhythm-related terms include 
notions of tempo and the kind of variation (acceleration, elastic fluctuation), accentuation and syncopation, regularity or even spacing, rhythmic repetition, and a few terms related to articulation. The only six timbrerelated terms were assigned to Class 3, referring to sonority, color, and roundness. In some cases, indications of mood or atmosphere were expressed, using terms such as energetic, assertive, urgent, gentle, tender, aggressive, violent, and so on.

As mentioned in the introduction, it should be borne in mind that the composer was not seeking to create a homogeneous set of subsections in each theme, but rather a complete musical idea that had interesting variation to it. Indeed, as these results demonstrate, while each theme has a characteristic place in the space of possible textures and moods, each one also diverges from this main character to other textures and moods. Theme 2 is a good example, as can be gleaned from Figure 1. It starts and ends with the alternation between fierce sforzando chords and rapid, soft grace-note figurations that are characteristic of its nature as Contradictory Assertion. All of the subsections that embody this character are tightly grouped together in the left subbranch of Class 2 . However, subsections 2.4 and 2.6 are running passages that are slurred and staccato, respectively. And indeed they are classed with subsections of other themes in Classes 1 and 3, respectively. They thus vary the character, giving Theme 2 a more interesting shape that modulates out from Class 2's aggressive, choppy, insistent nature to brief sojourns in Class 1's rapid, chromatic passages and Class 3's soft, regular cascades. In similar manner, Themes 1 and 4 move between the characters of three classes, and Themes 3 and 5 move between two classes.

\section{Experiment 2: Orchestral Versions}

The Angel of Death themes were also composed for a chamber orchestra of 16 musicians in order to present the thematic materials in parallel fashion with instrumentation change in the two parts of the piece. The instrumentation was the following:

- five strings: two violins, viola, cello, contrabass;

- four brass: French horn, two trumpets, trombone;

- four woodwinds: two flutes (each with a piccolo), clarinet, bass clarinet;

- three multiple percussion:

I. vibraphone, crotales, medium and high Tibetan cymbals, high gong;

II. xylophone, medium Tibetan cymbal, low gong, tam-tam;

III. marimba, triangle, low Tibetan cymbal, tam-tam. 
The principle of interchangeable media (piano vs. chamber orchestra) allowed us to explore the difference in musical similarity between materials in single- and multiple-instrument versions, with the wealth of timbral differentiation that the latter affords.

\section{METHOD}

\section{Participants}

Forty new participants with ages ranging from 18 to 54 years $(M=25, S D=8.1)$ performed the experiment. The independent group of participants was judged necessary to avoid previous experience with the piano versions influencing the classification of the orchestral versions. None of the listeners reported having hearing problems, and all were paid for their participation. Twenty had no musical experience (9 women) and 20 had from 5 to 30 years instrumental practice (11 women). Of the latter group, 4 were professional musicians and 16 were actively practicing amateurs.

\section{Stimuli, Equipment, and Procedure}

The number and division of subsections in the orchestral versions were identical to those of the piano versions. ${ }^{1}$ They were performed by the SONOR ensemble under the direction of Harvey Sollberger and were recorded in Warren Studio A in the Music Department at the University of California at San Diego. Instruments were individually miked and a stereo pair was used to capture room ambience. A digital 24-bit multitrack recording sampled at $48 \mathrm{kHz}$ was made. A stereo mix was made under the supervision of the composer for the purposes of the experiment. The mixes were converted to 16-bit stereo files with a sampling rate of $44.1 \mathrm{kHz}$. The subsections of the themes were extracted digitally from the sound files with appropriate rise and decay ramps applied as for the piano excerpts. The durations of the subsections varied from 2.1 to $30.7 \mathrm{~s}$. The full chamber orchestra was used for each theme, although the range of instrumentation varied for the individual subsections. The equipment and procedure were identical to those of Experiment 1.

\section{RESULTS}

Listeners formed from 3 to 12 classes $(M d n=$ mode $=6)$. A betweensubjects ANOVA on Gender (2) $\times$ Musical Expertise (2) revealed no significant effects (all $F<1$ ). The correlation between the cooccurrence matrices for musicians and nonmusicians was highly significant, $r(559)=$ $.83, p<.0001$. Consequently, the data from the two groups were combined for subsequent analyses as in Experiment 1.

\section{Cluster Analysis}

A hierarchical tree structure was computed from the group dissimilarity matrix by using the complete linkage method (Figure 3). Using the same threshold value of .9 as in Experiment 1, six different classes were differentiated within the tree. The correlation between the dissimilarity and cophenetic matrices shows that the tree structure represents $65 \%$ of the 


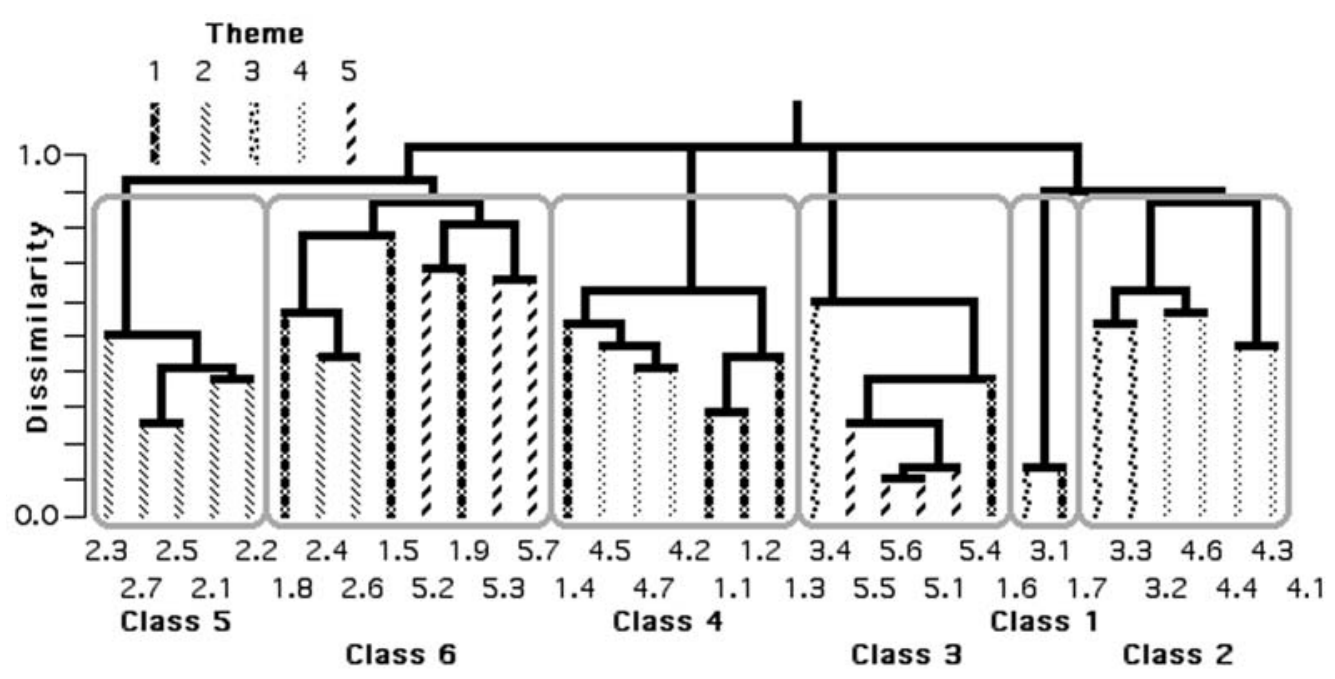

Fig. 3. Hierarchical clustering analysis (complete linkage method) of free classification data (Expt. 2) for the orchestral versions of thematic subsections. The labels of each final branch correspond to $<$ Theme.subsection $>$. The themes are distinguished by line textures.

variance in the data, $r(559)=.81, p<.0001$. The fit is thus less good for the orchestra classification than for the piano classification.

Figure 3 shows a greater dispersion of the subsections from a given theme in the orchestral version than in the piano version. Whereas Themes 1 and 2 still have $44 \%$ and $71 \%$, respectively, of their subsections in single classes (Classes 4 and 5, respectively), the other themes are split among two to four classes, indicating a greater variability in similarity relations within themes introduced by timbral factors.

It is important to note that there is no statistical difference in the number of classes formed for the piano and orchestra sets of subsections, $F(1,110)=1.3, p=.26$, nor any interaction of this factor with gender or musical expertise (all $p>.29$ ). The dissimilarities derived from the classifications of the piano excerpts explain $48 \%$ of the variance in those derived from the orchestral excerpts, $r(559)=.69, p<$ .0001 , indicating that the orchestration has a large effect on the perceived class structure. This difference is not due to the distribution of dissimilarity values. If the group dissimilarities, which vary between 0 and 1 , are grouped into bins of width .1, and the counts of bins from 1 to 1.0 are compared between the two distributions, there is no significant difference, $\chi^{2}(8)=7.7, p>.30$. So the differences between the two versions are neither in global distribution of dissimilarity nor in number of classes formed, but more in terms of the internal structure of the classes. 


\section{Verbalization Analysis}

A total of 231 classes were formed by the 40 participants, of which 225 had verbal units (six were labeled as "unclassifiable"). Table 2 summarizes the 160 verbal units produced by listeners, which were assigned to

\section{TABLE 2}

\section{Most Frequently Verbalized Groups of Similar Terms Assigned to the Six Classes of Orchestra Materials}

\begin{tabular}{|c|c|c|c|c|c|}
\hline Class 1 & Class 2 & Class 3 & Class 4 & Class 5 & Class 6 \\
\hline $\begin{array}{l}\text { Strings, violin, } \\
\text { nonpercussive } \\
(19)\end{array}$ & $\begin{array}{l}\text { Descending, } \\
\text { ascending } \\
\text { series, glissan- } \\
\text { do }(17)\end{array}$ & $\begin{array}{l}\text { Soft, calm, } \\
\text { appeasing, } \\
\text { peaceful, lan- } \\
\text { guorous, } \\
\text { agreeable, } \\
\text { romantic, } \\
\text { melodramatic, } \\
\text { nostalgic, } \\
\text { voluptuous, } \\
\text { melancholic, } \\
\text { sad }(25)\end{array}$ & $\begin{array}{l}\text { High/low } \\
\text { sonority/regis- } \\
\text { ter, bass } \\
\text { effect, similar } \\
\text { register, } \\
\text { high/low con- } \\
\text { trast/mixture, } \\
\text { low pitch, res- } \\
\text { onance (16) }\end{array}$ & $\begin{array}{l}\text { Choppy, jerky, } \\
\text { syncopated, } \\
\text { unbalanced/ } \\
\text { shifted rhythm, } \\
\text { rapid, brief, } \\
\text { detached, } \\
\text { untied, } \\
\text { unwoven, } \\
\text { destructured, } \\
\text { fragmented } \\
\text { (23) }\end{array}$ & $\begin{array}{l}\text { Percussive, } \\
\text { brass, winds, } \\
\text { marimba, } \\
\text { flute, piccolo } \\
(10)\end{array}$ \\
\hline $\begin{array}{l}\text { Soft, agreeable, } \\
\text { amusing, sen- } \\
\text { sation of ele- } \\
\text { vation, nostal- } \\
\text { gia, shrill, } \\
\text { stressful, dis- } \\
\text { sonant, irritat- } \\
\text { ing (13) }\end{array}$ & $\begin{array}{l}\text { Percussive, } \\
\text { xylophone, } \\
\text { marimba (3) }\end{array}$ & $\begin{array}{l}\text { Strings, violin, } \\
\text { nonpercussive, } \\
\text { lots of instru- } \\
\text { ments, bass } \\
\text { effect, cello, } \\
\text { xylophone, } \\
\text { winds, big } \\
\text { brass, color, } \\
\text { soft orchestra, } \\
\text { specific sonor- } \\
\text { ity (18) }\end{array}$ & $\begin{array}{l}\text { Shrill, aggres- } \\
\text { sive, danger, } \\
\text { increasing } \\
\text { pressure, } \\
\text { anguish, } \\
\text { oppressing, } \\
\text { grating, ten- } \\
\text { sion, appre- } \\
\text { hension (14) }\end{array}$ & $\begin{array}{l}\text { Brass, strings, } \\
\text { percussive, vio- } \\
\text { lin, timbre, } \\
\text { winds, marim- } \\
\text { ba, car horn, } \\
\text { cello, fanfare } \\
\text { (18) }\end{array}$ & $\begin{array}{l}\text { Jerky, choppy, } \\
\text { continuity of } \\
\text { the rhythm (3) }\end{array}$ \\
\hline $\begin{array}{l}\text { Descending, } \\
\text { ascending } \\
\text { series }(12)\end{array}$ & $\begin{array}{l}\text { Soft, agreeable, } \\
\text { amusing (3) }\end{array}$ & $\begin{array}{l}\text { Slow, same } \\
\text { tempo, contin- } \\
\text { uous rhythm, } \\
\text { waltz (16) }\end{array}$ & $\begin{array}{l}\text { Brass, lot of } \\
\text { instruments, } \\
\text { flute, percus- } \\
\text { sive, winds, } \\
\text { marimba, } \\
\text { dark color } \\
(10)\end{array}$ & $\begin{array}{l}\text { Lively, shrill, } \\
\text { chaotic, sur- } \\
\text { prise, violent, } \\
\text { energetic, } \\
\text { rebounding } \\
\text { (11) }\end{array}$ & $\begin{array}{l}\text { Energetic, live- } \\
\text { ly, peak of } \\
\text { intensity (3) }\end{array}$ \\
\hline $\begin{array}{l}\text { Rapid, acceler- } \\
\text { ating }(5)\end{array}$ & & $\begin{array}{l}\text { Melodic, con- } \\
\text { tinuous, fluid, } \\
\text { legato, a sin- } \\
\text { gle melody } \\
(10)\end{array}$ & $\begin{array}{l}\text { Chaotic, } \\
\text { untied, frag- } \\
\text { mented, } \\
\text { destructured, } \\
\text { jerky, choppy } \\
\text { (7) }\end{array}$ & $\begin{array}{l}\text { Low/bass, high, } \\
\text { similar register, } \\
\text { high/low mix- } \\
\text { ture }(5)\end{array}$ & \\
\hline $\begin{array}{l}\text { Jerky, precipi- } \\
\text { tated, furtive } \\
\text { (3) }\end{array}$ & & & $\begin{array}{l}\text { Ascending, } \\
\text { descending, } \\
\text { glissandi }(5) \\
\text { Similar } \\
\text { rhythm, rapid, } \\
\text { energetic, live- } \\
\text { ly, note dura- } \\
\text { tions (5) }\end{array}$ & & \\
\hline
\end{tabular}

Note- The total number of verbalizations represented by each set of terms is indicated in parentheses. The verbalizations were originally produced in French and are presented here in approximate translation. 
the classes in the tree structure as in Experiment 1. There were 34, 13, 36, 32,37 , and 8 units assigned to Classes 1-6, respectively. The first thing to note is the use of terms related to instrumentation and timbre to characterize all of the classes, as well as a higher relative number of terms of an affective or emotional nature compared to the verbalizations for the piano versions. Terms related to rhythm, melody, and gesture are still strongly present. Class 1 is characterized by the presence of stringed instruments, rapid, jerky upward and downward patterns, as well as by both positive and negative affective terms. Class 2 contains upward and downward patterns and glissandi, a predominance of percussion instruments, and positive affective terms. Class 3 is clearly multi-instrumental with a predominance of string identifications, slow tempi with a continuous melodic line accompanied by primarily positive affective terms. Class 4 is characterized by a high register and contrasts between high and low registers, is more strident and aggressive, with a predominance of brass and high flutes, and a chaotic, fragmented texture. Class 5 is also fragmented, syncopated and jerky texturally, with a predominance of brass and strings, and a lively, strident, and energetic character. Class 6 contains more percussion and brass identifications and a choppy, energetic texture.

As with the piano versions, the composer produced descriptions upon listening to the subsections that belonged to each of the six classes in the tree structure (before being exposed to the verbalization analysis).

- Class 1: Rapidity of motion. Patterns of pitch alternation. Registrally static. Very quiet, gentle mood. Nondirectional. String timbre.

- Class 2: Directional. Rapid and even motion. Graceful and fluid mood. Characteristics of the two subclasses:

a. (4.1, 4.3) Strong, linear directionality. Wide range. Timbrally heterogeneous, but blended.

b. (3.2, 3.3, 4.4, 4.6) More elastic, variable motion. Timbrally heterogeneous, but not well blended. More dynamically assertive.

- Class 3: Soloistic lines emerging from harmonic context. Rhythmic elasticity. Gentle, lyric mood. Harmonic stability.

- Class 4: Gesturally assertive. Low-register grounding by brass. Wide registral range (whether as a result of trajectories in Theme 4 or simultaneous lines in Theme 1 materials). Timbrally heterogeneous with intermittent soloistic character.

- Class 5: Gestural quirkiness (uneven, unpredictable events). Disjunct character. Staccato chords. Irregular spacing in time. Tendency towards reiteration. Harmonic consistency. Timbral variability.

- Class 6: Rapidity of motion. Gestural irregularity. Timbral distinctiveness. Characteristics of the two subclasses:

a. $(1.8,2.4,2.6)$ Staccato articulation. Timbral consistency throughout. Playful, animated mood. 
b. $(1.5,1.9,5.2,5.3,5.7)$ Irregularly placed sforzando accents (except for 5.7, which doesn't seem to belong here). Conjunct motion runs, figuration, iteration with irregular emphasis.

[N.B. The dynamic levels of the two subclasses are incoherent, (a) being much less strong than (b).]

The composer noted that the orchestral medium confuses the relative categorical clarity in comparison to the piano versions. Different, and sometimes seemingly irrelevant, features seem to have much more influence here when the isolated subsections are compared. For example, the weight of unmuted brass in comparison with staccato string passages in the different subsections of Theme 1 changes matters greatly. Some exceptions to this conclusion are perhaps Class $2 \mathrm{~b}$ and Class 5, in which diversity of orchestration is overridden by the cohesiveness and distinctiveness of the writing. Again the composer's and listeners' descriptions share many features in common, although the expression differs.

\section{DISCUSSION}

The classification of the orchestral subsections was more varied in terms of the relation between perceived classes and theme belongingness as well as in terms of the variety of verbalizations produced by the listeners to describe the classes. The orchestration of the thematic materials clearly adds additional factors that must be taken into account in performing the classification task.

To assess the role of global differences in instrumentation on the class structure, the number of measures in which a given instrument was present and clearly identifiable in a subsection was determined. These data were converted to the proportion of time the instrument was present over the excerpt, and individual instruments were combined into the classic families: strings, woodwinds, brass, and percussion (Figure 4). The woodwinds have a moderate presence in all classes (being a little lower in Class 1 and a little higher in Class 2). This family is thus not very diagnostic. More variation across classes is found for the other families. Strings are present throughout but are notably strong and dominant in Classes 1 and 5 , and the verbalizations reflect this. The brass are strongly present in Class 5, moderately present in Classes 4 and 6, and weak or absent in Classes 1,2, and 3, which correspond well with their relative prominence in the verbalizations. The percussion are weakly to moderately present in all classes with the exception of Class 1 , from which they are absent. Their verbalizations correspond less well, being predominant in Class 6. Thus the pattern of dominance of the instrument families clearly varies across the classes and corresponds fairly well to the verbalizations. 


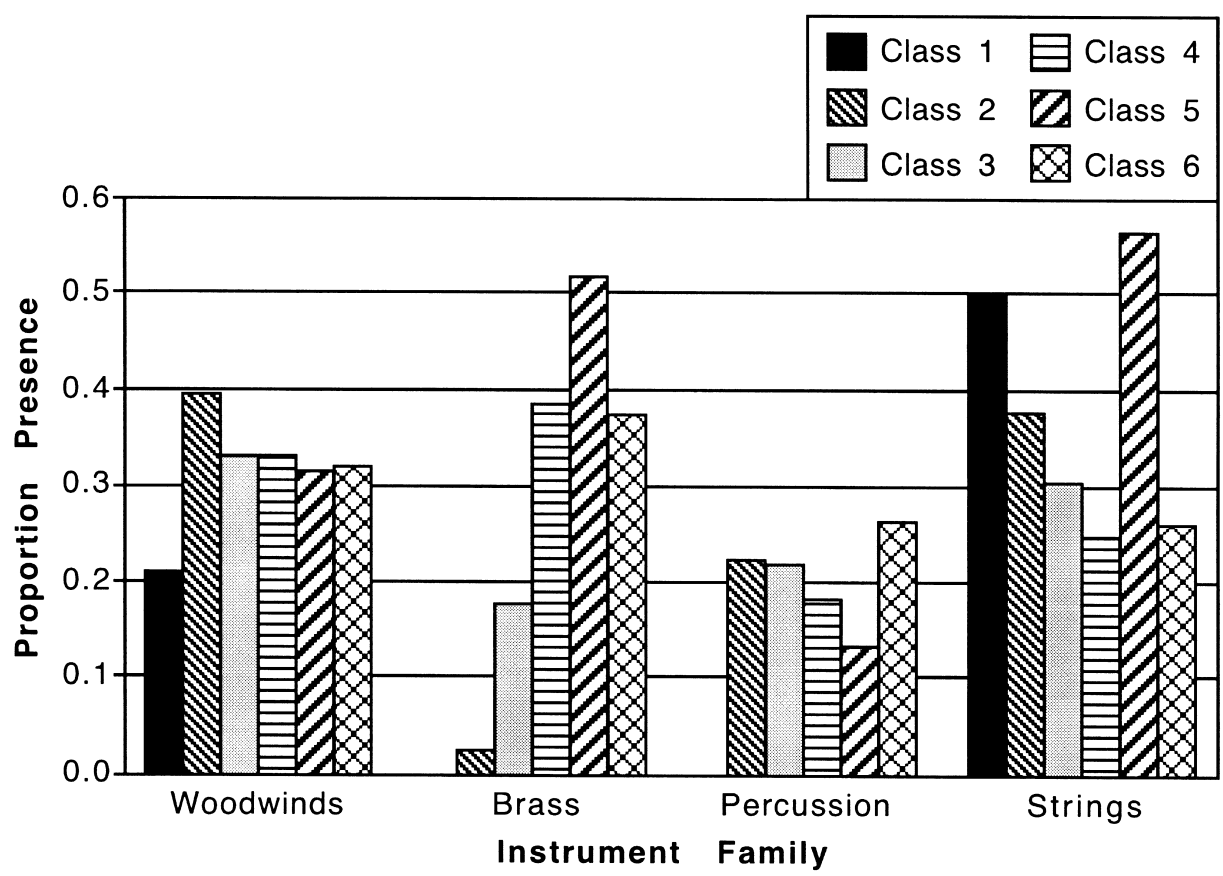

Fig. 4. Proportion presence of active instrument families across the subsections in the six classes derived from the orchestra tree structure in Figure 3.

It is instructive from this point of view to consider the changes in the tree structure between the two instrumentations. The group dissimilarities among subsections of the same themes in the piano and orchestral versions are significantly correlated (all $p<.0001$ ) for only three of the themes: $r(34)=.76$ for T1, $r(19)=.88$ for T2, and $r(19)=.74$ for T5. Themes 3 and 4 would thus seem to have been the most affected by the orchestration change in terms of intra-theme similarity relations. However, the changes are potentially due to both within-theme and crosstheme similarities and differences.

Theme 1 (Equilibrium in Extremis) subsections were found in three classes in the piano version and in four classes in the orchestral version. Subsection 1.6 remains apart with its gentle, harmonic affinity to 3.4 and 5.5 in both versions. The main changes are that 1.7 groups very strongly with 3.1 due to the soft, melodic alternation and string texture, leaving 1.8 which has joined with 2.4 and 2.6 with similar rapid woodwind and keyboard percussion passages. Subsection 1.9 leaves the 1.1-3 group to join 1.5, with which it shares sforzando brass events. Subsection 1.4 leaves 1.5 to join Theme 4 materials with rapid, wide-ranging, timbrally varying gestures. 
The main group of Theme 2 (Contradictory Assertion) subsections remains unified and the two subsections that were outliers in the piano versions $(2.4,2.6)$ acquire a greater affinity between them due to the rapid passagework that moves between instrument groups in similar registers. Rather than timbre per se, it is more the texture of timbral motion that links these two with 1.8 .

Theme 3 (Tremulous Uncertainty) is more dispersed in the orchestral version. Subsection 3.1 joins 1.7 as previously mentioned, and 3.4 remains close to 1.6 and 5.5 , as in the piano version.

Theme 4 (Jagged Rips) relations are strongly rearranged as a result of orchestration as shown by the low correlation between piano and orchestra dissimilarities, $r(19)=.22$. In the piano version, there was a main group $(4.1,4.2,4.3,4.5,4.6)$ with two outliers $(4.4,4.7)$. Subsection 4.7 in the piano version is the single subsection with the greatest mean dissimilarity compared with all the others (.81). In the orchestral version, the main group splits in two, and each subgroup picks up one of the previous outliers, creating two groups that are now associated with Theme 3 materials for one and with Theme 1 materials for the other. They are distinguished by one group $(4.1,4.3,4.4,4.6)$ having mid- to high-register, rapid passage work in woodwinds and strings, and the other $(4.2,4.5$, 4.7) with a greater presence of brass, a wider registral extent, and a grounding with low brass and strings. These timbral and textural characteristics also explain the affinity of Theme 4 subsections with the Theme 3 and Theme 1 materials, respectively.

Theme 5 (Interior Line) was organized into two separate classes in the piano version, as is the case in the orchestral version, except that there is a crossover of 5.7 to join with 5.2 and 5.3, and with 5.5 being closer to $5.1,5.4$, and 5.6. The former group is texturally more disjointed and fragmented by the timbre changes, whereas the latter group has a more continuous, linear timbre change that is consistent with the linear melodic structure. In particular, the sforzando brass notes in the latter group create a moderate affinity with 1.9.

This analysis suggests that not only is orchestration a strong factor in the perception of musical similarity, that is, timbre per se creates affinities among musical materials, but the kinds of timbral gestures and textures that are created (continuous, smooth paths as opposed to more discontinuous, fragmented structures that jump around in timbre space) are also important. In many cases, timbral factors strongly coincide with pitchbased factors (covariation of timbre with register, for example). However, whereas the timbral forces, primarily through their effects on auditory scene analysis (continuity vs. fragmentation as described above), can change the perceived texture considerably, at times similarity of pitch and rhythmic configuration can override timbral differences, as is evidenced in 
the Theme 2 and Theme 5 groupings that are similar across the two instrumentations.

\section{General Discussion}

The analyses of factors involved in grouping the thematic subsections, by examining the musical excerpts and the verbal data, strongly suggest that listeners preferentially used the surface features of the musical materials to determine the musical similarity relations among subsections. Again, this is perhaps not surprising given that these findings are coherent with those presented in other studies (Addessi \& Caterina, 2000; Deliège, 1989; Deliège \& El Ahmadi, 1990; Lamont \& Dibben, 2001; McAdams \& Matzkin, 2003) showing the importance of surface features in the perception and processing of both tonal and nontonal musical structures. Perhaps related to the fact that our task involved immediate comparison of musical materials, our results are coherent with the findings of Bartlett and Dowling (1980), who found that such features dominate short-term contexts. The sensitivity to these features was not affected in a systematic way by formal musical training or musical practice, although the vocabulary used to express them differed between musicians and nonmusicians. Lamont and Dibben (2001) have also found equivalent performance between musicians and nonmusicians for similarity ratings and marginally significant differences for adjective ratings.

The general types of surface features suggested by the verbalization analyses and the descriptions of the group classes by the composer include duration/rhythm, pitch/melody, timbre, gesture, texture, articulation and to a lesser extent dynamics and harmony. In many cases, these types are overlapping and interdependent (e.g., gesture and texture can involve melodic, rhythmic, and timbral variation). For duration and rhythm, features such as tempo and types of tempo variation, continuity of durational patterns (regularity/irregularity), accentuation, and syncopation were mentioned. Terms related to pitch and melody include register, contour, interval size, degree of repetition of elements, and number of perceived lines. Gesture and texture include notions of directionality, continuity/fragmentation, elasticity/consistency, fluidity/choppiness, and linear/rebounding. A few rare mentions of articulation (staccato, hammered, legato, etc.) and dynamics (soft, loud, peak of intensity) were found. All of these types of terms were found for both piano and orchestral versions. Not surprisingly, timbre-related terms were much more frequent in the orchestral version. For the piano, this type of descriptor was limited to expressions related to sonority, roundness, or color (six descriptors produced for one of the four classes). For the orchestra, mention of 
specific instruments or instrument families was frequent (77 descriptors produced across all six classes). However, there was also expression of the degree of consistency, multiplicity, variability or distinctiveness of the timbral palette, indicating a sensitivity not only to timbre per se, but to the style of timbral change, which was used with specific esthetic goals in mind by the composer (see Reynolds, 2004). Future work will need to formalize the contributions of the various surface cues indicated by the verbalizations in this study in order to create predictive models of musical similarity and classification. At present, however, the way to characterize the cues quantitatively and then develop a realistic framework to combine them into a similarity measure does not seem so obvious.

Another class of descriptor employed several times for the piano versions (23 descriptors) and much more frequently for the orchestral versions (61 descriptors) involved the mood or atmosphere evoked by the excerpts. The more affective descriptors clearly involved an abstraction of a general feeling created by the probable combinations of several surface features that form the excerpt and may be particularly sensitive to instrumentation differences and performance parameters. To our knowledge, there is no previous report of such factors playing a role in musical similarity perception or in the categorization of musical excerpts. The kinds of moods expressed vary from quite positive (peaceful, languorous, calm, amusing, playful) through more melancholic and nostalgic to quite negative (aggressive, violent, irritating, sense of danger, anguish). This result makes one wonder whether previous research on musical similarity has not tapped into this realm of experience due to the kinds of constraints placed on listeners' responses or to the simple musical materials used. With all of the methodological problems that free verbalization raises, it would at least seem to have the advantage of revealing previously unsuspected factors that play a role in the perception of musical similarity. What this may reveal to us about musical categorization processes with real music is that listeners can, and indeed in some cases are inclined to, use more affective properties that emerge from the combination of acoustic features to compare and contrast musical excerpts. It also clearly indicates that similarity can have both direct perceptual cues, such as the surface cues described in detail earlier, as well as more cognitively derived cues, such as the affective results of those cues, that implicate associative processes between the perceptual structure and past affective experience.

One aspect of musical similarity that the current study allowed us to examine is the effect of differences in instrumentation on otherwise nearly identical musical materials. Slightly less than half the variance in the dissimilarity relations among the orchestral excerpts was explained by the piano versions, which have much less timbral variation due to the relative- 
ly homogeneous timbre of the grand piano across its pitch range. Two points are of interest in these data: the similarity relations that resisted or were reinforced by orchestration and those that were significantly modified by orchestration.

In the case of musical similarity in spite of timbral difference, some melodic/rhythmic writing is characteristic enough to strongly resist timbral change or was orchestrated such that the melodic/rhythmic signature was preserved by the orchestration. Two examples in the present study are the large groups of subsections from Themes 2 and 5 that remain together in both versions. In five of the Theme 2 subsections (excluding 2.4 and 2.6), the key diagnostic feature is the alternation between strongly attacked sforzando chords and softer, rapid grace-note figures. While the $s f f z$ chords are orchestrated in different ways, changing combinations of instrument families from one chord to the next, the alternation characteristic is strong enough to override the timbral change. In Theme 5, the diagnostic feature is the slow, lyrical melodic line in most of the sections. This line is orchestrated in Klangfarbenmelodie style by having smooth transitions between instruments (or combinations of instruments in unison or octave doublings) with similar timbre every few notes. So although the timbre changes considerably compared to the piano version, the linear character is preserved by a judicious orchestration.

The cases in which orchestration results in a rearrangement of the affinities in the piano version are numerous, and one example based on the reorganization of Theme 4 subsections will suffice to illustrate the principle. In the piano version, 4.1, 4.5 and 4.6, on the one hand, and 4.2, 4.3 and 2.4, on the other, formed subclasses in Class 1 . Subsection 4.7 was pretty much alone within Class 4 , although distantly related to subsections from Theme 5. Subsection 4.4 was in a subclass in Class 3 with the first three subsections of Theme 3. What distinguished these groups was that Class 1 consisted of rapid, wide-ranging, upward and downward trajectories (the jagged rips characteristic of this theme), 4.7 was an accelerating, wide, upward trajectory, and Class 3 contained smooth, fluttering pitch alternations in a constant register. The subsections distributed across three classes in the piano, regrouped into two classes in the orchestral version, also changing their affinities with subsections from other themes. In Class 2, Subsection 4.4 stayed with 3.2 and 3.3, but was joined by 4.1, 4.3 and 4.6 , which were previously grouped in the piano version. In Class $4,4.2$, and 4.5 were joined by 4.7 and the first four subsections of Theme 1. Both groups are timbrally heterogeneous, but what distinguishes them is the balance of instrument families, the assignment of instruments to register, and the way timbral change within each subsection affects the texture. In Class 2, there is a predominance of strings and woodwinds with no brass, whereas Class 4 has very strong brass and much less woodwind 
presence. In Class 2, most of the subsections occupy the medium and high registers, whereas in Class 4 very low notes are present and are given great weight by low brass and contrabass. Finally, timbral changes are dealt with quite differently in the two classes, there being a much greater tendency for timbral continuity and overlap in Class 2, whereas Class 4 has more disjunctive timbral writing that underlines the fragmented and chaotic nature of its excerpts. It is clear that not only can orchestration change, but also the way the material is orchestrated can modulate texture and dramatic impact to a significant extent.

The patterns in the data presented here clearly demonstrate that listeners can potentially understand musical similarity relations in contemporary music and that this ability is fairly independent of musical training. Moreover, the composer's own intuition concerning the way listeners could perceive and characterize relations among the thematic subsections is largely corroborated by the behavioral responses reported here (see Reynolds, 2004). The emphasis of listeners' classification criteria on surface features and mood is coherent with the gestural/textural and dramatic conception of the different thematic characters.

The exploration of the perceptual structure of these materials was of course performed outside of the context of the piece, as the piece was not yet written. It is nonetheless worth considering the impact of the similarity relations on possible material interactions within the final piece. As briefly stated in the introduction (and developed more fully in Reynolds, 2004), there are several occasions and contexts within which materials derived from different thematic subsections appear simultaneously, sometimes in the same instrumentation and other times in separate instrumentations. In terms of instrumental writing, these include the combination (COMB, combinations of materials from different themes) and transition (TR, transition from a predominance of materials from one theme to that of another theme) sections of the Sectional part of the piece (COMB 2/4, TR1 $\rightarrow 3$, TR2 $\rightarrow 4$ ) as mentioned in the introduction. Throughout the Domain part of the piece, thematic materials from different themes often overlap (T1, T2, T3 near the beginning; T2, T3, T4, T5 in the middle; T1, $\mathrm{T} 2, \mathrm{~T} 3, \mathrm{~T} 5$ at the end). If, in line with the belongingness judgments analyzed on these thematic materials by Lalitte et al. (2004), we take as a hypothesis that materials from different themes that are coexistent would be more likely to be confused or blended the more similar they are, this leads us to study the overlapping regions in the full score that are derived from particular subsections belonging to the same classes in the tree structure. The large majority of overlapping regions concern one material in piano and the other in orchestra. We may safely assume that their interaction would be lessened by the clear instrumentation difference in these cases (cf. Poulin-Charronnat et al., 2004). In the Sectional part, a small number of overlaps of same-class subsections occurs in TR $1 \rightarrow 3$ played by 
the piano: 1.4-5/3.1-3 (Class 3), 1.6/3.4 (Class 4). No same-section overlaps occur in COMB2/4 or TR $2 \rightarrow 4$. In the Domain part, only four brief overlaps of same-class materials occur: 2.4/4.3 and 2.4/4.5 (Class 1 in piano), and 3.4/5.4 and 1.6/3.4 (Class 3 in orchestra). Globally, we thus observe that the composer avoided overlapping materials that were too similar in nature and that would risk not maintaining their thematic distinction.

McAdams and Matzkin (2003) have pointed out the crucial role of similarity cues for the integration of the musical structure and a comprehension of its global form. The concept of similarity refers to the degree of match between the properties and features of two or more musical materials, whose patterns are formed along different dimensions such as timbre, pitch, intensity, or duration of musical events. According to Deliège (1989), similarity and difference constitute the organizing principle underlying contextualized music perception. In her study of the perception of musical form in nontonal music, musician and nonmusician listeners were asked to make segmentations within musical pieces according to the musical structure they perceived. Results revealed that whatever their level of musical expertise, listeners gave similar group boundaries. The consistency of responses in this segmentation task revealed that musical cues such as pitch changes and timbre were used as perceptual invariants in order to locate group boundaries. Her findings indicate that listeners essentially focused on the surface level of musical structure without using musical relations at higher hierarchical levels. Addessi and Caterina (2000) also found that criteria applied by listeners essentially depend on surface elements, such as variations in intensity and timbre, as well as rhythmic elements. Generally, it is encouraging to note that basic perceptual processing of musical similarity is operative in both traditional tonal music and in less familiar contemporary musical styles. Although work similar to the present study has not been specifically performed to compare the similarity relations that are operative in tonal and nontonal music, it seems likely, at least for listeners inexperienced with nontonal music, that overlearned hierarchical schemata might play a stronger role in similarity perception. With repeated listening, however, one might hope, extrapolating Goldstone (1994) to the musical realm, that musical categorization processes based on perceptual and mood similarities could create the ground from which deeper commonalities would evolve in the understanding of contemporary music. ${ }^{4}$

4. The authors thank Jean-Marie Cottet, Franck Rossi, and Alain Jacquinot for the piano recordings, Harvey Sollberger, the SONOR ensemble, Josef Kucera, and Benjamin Carson for the orchestra recordings, Bennett Smith for programming the experimental interface, and François Madurell and Emmanuel Bigand for advice and many fruitful discussions on this work. The work was funded by the Cognitique program of the French Ministry of Research, and benefited from support from IRCAM-Centre Pompidou and the University of California at San Diego. 


\section{References}

Addessi, A., \& Caterina, R. (2000). Perceptual musical analysis: Segmentation and perception of tension. Musicae Scientiae, 4, 31-54.

Bartlett, J., \& Dowling, W. J. (1980). Recognition of transposed melodies: A key-distance effect in developmental perspective. Journal of Experimental Psychology: Human Perception and Performance, 6, 501-515.

Bigand, E. (1990). Abstraction of two forms of underlying structures in a tonal melody. Psychology of Music, 18, 45-60.

Daws, J. (1996). The analysis of free-sorting data: Beyond pairwise cooccurrences. Journal of Classification, 13, 57-80.

Deliège, I. (1989). A perceptual approach to contemporary musical forms. Contemporary Music Review, 4, 213-230.

Deliège, I., \& El Ahmadi, A. (1990). Mechanisms of cue extraction in musical groupings: A study of perception on Sequenza VI for viola solo by L. Berio. Psychology of Music, $18,18-44$.

Dibben, N. (1994). The cognitive reality of hierarchical structure in tonal and atonal music. Music Perception, 12, 1-25.

Dibben, N. (1999). The perception of structural stability in atonal music: The influence of salience, stability, horizontal motion, pitch commonality, and dissonance. Music Perception, 16, 265-294.

Estes, W. K. (1994). Classification and cognition. Oxford: Oxford University Press.

Goldstone, R. (1994). The role of similarity in categorization: Providing a groundwork. Cognition, 52, 125-157.

Kruskal, J. (1977). The relationship between multidimensional scaling and clustering. In J. Ryzin (Ed.), Classification and clustering (pp. 17-44). New York: Academic Press.

Lalitte, P., Bigand, E., Poulin-Charronnat, B., McAdams, S., Delbé, C., \& D’Adamo, D. (2004). The perceptual structure of thematic materials in The Angel of Death. Music Perception, 22, 265-296.

Lamont, A., \& Dibben, N. (2001). Motivic structure and the perception of similarity. Music Perception, 18, 245-274.

Lerdahl, F. (1989). Atonal prolongational structure. Contemporary Music Review, 4, 65-87.

Lerdahl, F., \& Jackendoff, R. (1983). The generative theory of tonal music. Cambridge, MA: MIT Press.

Lindemann, E., Dechelle, F., Smith, B., \& Starkier, M. (1991). The architecture of the IRCAM Musical Workstation. Computer Music Journal, 15(3), 41-50.

Matzkin, D. (2001). Perception de similarité de mélodies tonales et non tonales: Etude pluridisciplinaire [Perception of similarity of tonal and nontonal melodies: An interdisciplinary study]. Unpublished doctoral dissertation, Ecole des Hautes Etudes en Sciences Sociales, Paris.

McAdams, S. (1989). Psychological constraints on form-bearing dimensions in music. Contemporary Music Review, 4, 181-198.

McAdams, S., \& Battier, M. (Eds.). (2005). Creation and perception of a contemporary musical work: The Angel of Death by Roger Reynolds [E-book]. Paris: IRCAM-Centre Pompidou.

McAdams, S., \& Matzkin, D. (2003). The roots of musical variation in perceptual similarity and invariance. In I. Peretz \& R. Zatorre (Eds.), The cognitive neuroscience of music (pp. 79-94). Oxford: Oxford University Press.

Medin, D., \& Schaffer, M. (1978). Context theory of classification learning. Psychological Review, 85, 207-238.

Nosofsky, R. (1986). Attention, similarity, and the identification-categorization relationship. Journal of Experimental Psychology: General, 115, 39-57.

Nosofsky, R. (1992). Exemplar-based approach to relating categorization, identification, and recognition. In F. Ashby (Ed.), Multidimensional models of perception and categorization. Hillsdale, NJ: Erlbaum. 
Poulin-Charronnat, B., Bigand, E., Lalitte, P., Madurell, F., Vieillard, S., \& McAdams, S. (2004). Effects of a change in instrumentation on the recognition of musical materials. Music Perception, 22, 239-263.

Reynolds, R. (2001). The Angel of Death, for piano solo, chamber orchestra and computer processed sound. New York: C. F. Peters.

Reynolds, R. (2004). Compositional strategies in The Angel of Death for piano, chamber orchestra and computer processed sound. Music Perception, 22, 173-205.

Rips, L. (1989). Similarity, typicality, and categorization. In S. Vosniadu \& A. Ortony (Eds.), Similarity, analogy, and thought (pp. 21-59). Cambridge: Cambridge University Press.

Rosch, E. (1978). Principles of categorization. In E. Rosch \& B. Lloyd (Eds.), Cognition and categorization (pp. 27-48). London: Erlbaum.

Serafine, M. L., Glassman, N., \& Overbeek, C. (1989). The cognitive reality of hierarchic structure in music. Music Perception, 6, 397-430.

Smith, B. K. (1995, June). Psiexp: An environment for psychoacoustic experimentation using the IRCAM Musical Wordstation. Paper presented at the meeting of the Society for Music Perception and Cognition, Berkeley, CA.

Tversky, A. (1977). Features of similarity. Psychological Review, 84, 327-352. 